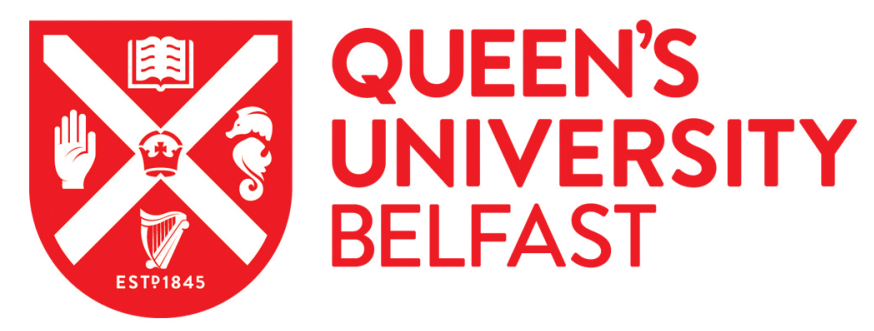

\title{
A preliminary structural design procedure for laser beam welded airframe stiffened panels
}

Wilson, R., Murphy, A., Price, M. A., \& Glazebrook, C. (2012). A preliminary structural design procedure for laser beam welded airframe stiffened panels. Thin-Walled Structures, 55, 37-50.

https://doi.org/10.1016/j.tws.2012.03.003

\section{Published in:}

Thin-Walled Structures

Document Version:

Peer reviewed version

Queen's University Belfast - Research Portal:

Link to publication record in Queen's University Belfast Research Portal

\section{Publisher rights}

This is the author's version of a work that was accepted for publication in Thin-Walled Structures. Changes resulting from the publishing process, such as peer review, editing, corrections, structural formatting, and other quality control mechanisms may not be reflected in this document. Changes may have been made to this work since it was submitted for publication.

\section{General rights}

Copyright for the publications made accessible via the Queen's University Belfast Research Portal is retained by the author(s) and / or other copyright owners and it is a condition of accessing these publications that users recognise and abide by the legal requirements associated with these rights.

Take down policy

The Research Portal is Queen's institutional repository that provides access to Queen's research output. Every effort has been made to ensure that content in the Research Portal does not infringe any person's rights, or applicable UK laws. If you discover content in the Research Portal that you believe breaches copyright or violates any law, please contact openaccess@qub.ac.uk. 


\title{
A Preliminary Structural Design Procedure for Laser Beam Welded Airframe
}

\section{Stiffened Panels}

\author{
R. Wilson ${ }^{\mathrm{a}}$, A. Murphy ${ }^{\mathrm{a}, *}$, M.A. Price ${ }^{\mathrm{a}}$ and C. Glazebrook ${ }^{\mathrm{b}}$ \\ ${ }^{a}$ School of Mechanical and Aerospace Engineering, Queen's University Belfast, \\ Ashby Building, Belfast. N. Ireland, U.K. BT9 5AH \\ ${ }^{b}$ Constellium CRV, Unité Aéronautique et Laminés Technique, Centre de Recherches \\ de Voreppe Centr'Alp, BP 27, 38341 Voreppe Cedex France
}

\begin{abstract}
Initial sizing procedures for aircraft stiffened panels that include the influence of welding fabrication residual process effects are missing. Herein, experimental and Finite Element analyses are coupled to generate knowledge to formulate an accurate and computationally efficient sizing procedure which will enable designers to routinely consider panel fabrication, via welding, accounting for the complex distortions and stresses induced by this manufacturing process. Validating experimental results demonstrate the need to consider welding induced material property degradation, residual stresses and distortions, as these can reduce static strength performance. However, results from fuselage and wing trade-studies, using the validated sizing procedure, establish that these potential reductions in strength performance may be overcome through local geometric tailoring during initial sizing, negating any weight penalty for the majority of design scenarios.
\end{abstract}

Keywords: Laser Beam Welding, Static strength performance, Stiffened panel design.

* Corresponding author: Tel.: +4428 9097 4095; fax: +4428 9066 1729. E-mail address: a.murphy@qub.ac.uk (Adrian Murphy). 


\subsection{Introduction}

\subsection{Background}

Riveting has been the principle joining process in aircraft manufacture since the 1920 's. It has been developed over the decades and is now a mature technology which has been significantly automated. Welding research is currently underway to replace riveting as the primary fabrication method for stiffened panels, as cost and weight reductions directly related to riveting fabrication is now limited to material improvements. The key advantage of welding is the speed of the joining process when compared to riveting [1]. In addition the removal of fasteners and sealant can also reduce manufacturing costs and the final weight of the fabricated panel [2-4].

As Laser Beam Welding (LBW) generates low distortion and excellent mechanical properties it is a promising welding process for assembling the thin-walled components found in typical aircraft panels [5]. Figure 1 illustrates the major differences between a riveted and LBW panel joint. LBW can achieve joining speeds up to 10 meters per minute in comparison to the 0.25 meters per minute achieved by traditional auto-riveting [6]. However, there are a number of process and design effects associated with welding which are much greater than in riveted assemblies:

1. Local material property degradation - the heat applied during welding alters the microstructure and reduces the local aluminium material properties.

2. Residual stresses - the weld heating and consequent joining and cooling introduces residual stresses and these can cause panel geometric distortions.

3. Fatigue and damage tolerance - the panel component junctions found in traditional built-up riveted structures will act as natural crack stoppers. A welded 
structure behaves as a single integral component, thus an initiated crack may propagate through the fabricated skin and stiffeners with no natural crack arresting features.

\subsection{Aim}

Within the aircraft preliminary design stage the global structural configurations for wing, fuselage and empennage are identified, along with their material components and manufacturing processes. If new fabrication techniques are to be extensively employed, it is at this stage that the designer must be able to assess their suitability. To achieve this, the designer needs a tool that can predict structural performance accurately yet is computationally inexpensive. For traditional stiffened panels, simple plate and column analysis techniques have been validated for this task but when attempting to incorporate new welding methods and their residual process effects these techniques are missing potentially important characteristics. Various generic methods are available to model the individual welding induced residual effects on strength performance. However an integrated and validated procedure is not available which can quantify such residual stress effects and identify which require representation within the initial design.

Thus the aim of this paper is to formulate and validate the modification which can be used with the conventional inexpensive panel sizing procedure to account for the influence of welding process residual effects on static strength. To achieve this aim individual analytical models, available in the literature, will be proposed for use within the conventional analysis procedure for the most significant residual effects. 
Coupled panel experimental testing and detailed Finite Element (FE) simulation of the tests will be used to determine the most significant residual effects. Moreover the experimental work will generate data on the magnitude of representative LBW residual effects and validate the proposed modifications to the conventional sizing procedure. Finally with the modified procedure, design studies will be undertaken to quantify the influence of residual effects on aircraft panel structural efficiency.

\subsection{Paper synopsis}

The article is organised as follows: Section 2 summarizes the conventional panel sizing procedure; Section 3 introduces LBW, its residual process effects, along with pertinent analytical models from the literature; Sections 4 and 5 detail the validating experimental and computational analysis respectively; Section 6 documents the combined modifications to the conventional panel sizing procedure along with the results from its experimental validation; Section 7 delivers the fuselage and wing trade-study results using the new validated sizing procedure; Finally Section 8 concludes the article with a summary of the key findings.

\subsection{Conventional aircraft panel sizing}

The conventional aircraft panel sizing procedure employs empirical and semiempirical formulae, idealising the panel structure as a series of plates and columns. This simplifies the problem and allows conservative approximations to be made for buckling and collapse behaviour. Fatigue and damage tolerance is not typically 
examined in detail but considered through the application of working stress targets and geometric design practice and constraints. Therefore behaviour under compression loading is of principal concern and thus summarised here.

\subsection{Static strength behaviour}

Stiffened panels can be designed to operate in the post-buckled region, which means that the skin sections may experience local buckling without panel collapse. At initial buckling the stress in the panel is uniform but once the post-buckling region is entered the stress distribution changes. As the load is increased the stress at the centre of the buckled skin bay theoretically remains at the buckling stress while the stabilising effect of the stiffeners enables the skin stress in the vicinity of the stiffeners to increase. The part of the skin that continues to act with the stiffener is known as the effective width and is considered part of the post-buckling stiffener column. The column behaviour of the stiffeners facilitates the additional load carrying capabilities of the panel, and panel failure occurs when the post-buckling stiffener column becomes unstable or yields.

\subsection{Skin buckling}

The skin between the stiffeners is idealized as a plate, with its buckling stress, $\sigma_{\text {skin, }}$ calculated using classical thin plate theory, as shown in Equation 1. This states that the critical stress is a function of the skin thickness, $t$, the skin bay width, $b$, and a buckling coefficient, $\mathrm{k}$, which is dependent on the aspect ratio of the skin bay and its edge boundary conditions. To account for non-linear material behaviour the 
calculation also considers the material tangent modulus, $\mathrm{E}_{\mathrm{t}}[7]$ and the material Poisson's ratio, $v$.

$$
\sigma_{\text {skin }}=\frac{k \pi^{2} E_{t}}{12\left(1-v^{2}\right)}\left(\frac{t}{b}\right)^{2} \quad \text { Equation } 1
$$

\subsection{Panel collapse}

Panel column collapse can occur in one of a number of ways. The simplest mode is pure flexural buckling, in which the column cross-section remains stable but the column flexes along its length. The flexural buckling stress, defined in Equation 2, occurs in columns with high slenderness ratios and is a function of the column effective length, 1', and the column section radius of gyration, $\rho$. As before, to account for material non-linear behaviour the equation also includes the material tangent modulus.

$$
\sigma_{\text {flexural }}=\frac{\pi^{2} E_{t}}{(1 / \rho)^{2}}
$$

Equation 2

For columns with low slenderness ratios combined buckling and material yielding of the column cross section can occur, typically called crippling. The web and flange elements of the column can be considered as individual plates. As each of these web and flange elements buckle the stress distribution changes and stress levels build at the stabilised element intersections. It is when these stresses reach the material yield 
stress that failure is said to occur. The column crippling stress, $\sigma_{\text {column, }}$, can be predicted with a weighted average calculation of the individual element crippling stresses, $\sigma_{\text {element, }}$ which in turn can be calculated using an empirical relationship which considers both local element buckling stress, $\sigma_{\text {buckle, }}$ and the local element material compressive yield stress, $\sigma_{\mathrm{cy}} . \sigma_{\text {element }}$ and $\sigma_{\text {column }}$ are defined as shown in Equation 3 and 4.

$$
\begin{array}{ll}
\sigma_{\text {element }}=\sqrt{\sigma_{\text {cy }} \sigma_{\text {buckle }}} & \text { Equation } 3 \\
\sigma_{\text {column }}=\frac{\sum b_{\mathrm{n}} \mathrm{t}_{\mathrm{n}} \sigma_{\text {element }}}{\sum \mathrm{b}_{\mathrm{n}} \mathrm{t}_{\mathrm{n}}} & \text { Equation } 4
\end{array}
$$

Examining intermediate slenderness ratios, column collapse is characterised with a combination of flexural behaviour and either local section yielding or crippling. Consider for example a column which initially begins to flex, the stress distribution across the section will change with additional bending compression stress induced. This may instigate local yielding leading to reduced bending stiffness, further bending and thus further yielding and ultimately section failure. This interaction of local yielding (or buckling) and column flexure maybe analysed using Equation 5 which gives the maximum stress allowed, $\sigma_{\max }$, is a function of the tangent modulus of the material and the average column stress, $\sigma_{\text {ave. }}$ Where the value of the average column stress, $\sigma_{\text {ave }}$, is calculated such that a maximum critical stress, $\sigma_{\max }$, is experienced at the column extreme fibres. The maximum critical stress is the lower of either the local web or flange element crippling stress or the material yield stress. To fully account for 
the column geometry the equation includes the column effective length, and the column initial imperfection eccentricity, e, along with the distance from the neutral axis of the column section to the section extreme fibre, $y$, and the section radius of gyration.

$$
\sigma_{\max }=\sigma_{\mathrm{ave}}\left[1+\frac{\text { ey }}{\rho^{2}} \sec \left(\frac{l^{\prime}}{2 \rho} \sqrt{\frac{\sigma_{\mathrm{ave}}}{\mathrm{E}_{\mathrm{t}}}}\right)\right]
$$

\section{Equation 5}

In addition torsional modes of instability are also possible. Pure torsional instability is characterized by twisting of the column about a longitudinal axis in the plane of the panel skin. The critical torsional stress, $\sigma_{\text {tor }}$, is a function of the column torsional constant, J, warping constant, $\Gamma$, column polar moment of inertia, $\mathrm{I}_{\mathrm{p}}$, along with the column material shear modulus and is defined in Equation 6. Moreover, flexural buckling can occur in combination with torsional instability, referred to as torsionalflexural buckling, the critical stress is found by resolving the cubic shown in Equation 7, which includes the critical column buckling stress about the $\mathrm{x}$-axis, $\sigma_{\mathrm{x}}$, the critical buckling stress about the $y$-axis, $\sigma_{\mathrm{y}}$, and the critical torsional buckling stress, $\sigma_{\text {Tor }}$. Additional parameters include the material tangent modulus, the column effective length, and the distance of the shear centre from the column principal axes, $\mathrm{x}_{0}$ and $\mathrm{y}_{0}$.

$$
\begin{gathered}
\sigma_{\text {Tor }}=\frac{G J}{I_{\mathrm{P}}}+\frac{\pi^{2} \mathrm{E}_{\mathrm{t}} \Gamma}{\mathrm{I}_{\mathrm{P}} \mathrm{l}^{2}} \quad \text { Equation } 6 \\
{\left[1-\frac{\mathrm{E}_{\mathrm{t}}}{\sigma_{\mathrm{tf}}} \frac{\sigma_{\mathrm{x}}}{\mathrm{E}_{\mathrm{t}}}\right]\left[1-\frac{\mathrm{E}_{\mathrm{t}}}{\sigma_{\mathrm{tf}}} \frac{\sigma_{\mathrm{y}}}{\mathrm{E}_{\mathrm{t}}}\right]\left[1-\frac{\mathrm{E}_{\mathrm{t}}}{\sigma_{\mathrm{tf}}} \frac{\sigma_{\mathrm{Tor}}}{\mathrm{E}_{\mathrm{t}}}\right]-\left[1-\frac{\mathrm{E}_{\mathrm{t}}}{\sigma_{\mathrm{tf}}} \frac{\sigma_{\mathrm{x}}}{\mathrm{E}_{\mathrm{t}}}\right]\left[\frac{\mathrm{y}_{0}}{\mathrm{l}^{\prime}}\right]^{2}-\left[1-\frac{\mathrm{E}_{\mathrm{t}}}{\sigma_{\mathrm{tf}}} \frac{\sigma_{\mathrm{y}}}{\mathrm{E}_{\mathrm{t}}}\right]\left[\frac{\mathrm{x}_{0}}{\mathrm{l}^{\prime}}\right]^{2}=0}
\end{gathered}
$$




\section{Equation 7}

For the full description of the analysis methods summarised here, the reader is referred to Bruhn [8], NASA Astronautics Structures Manual [9] and the ESDU Structures Sub-series [10]. Having introduced the panel stability behaviour and predictive calculations used for initial sizing the following Section examines the LBW process and its residual effects which may influence stability behaviour.

\subsection{Welding process effects}

\subsection{Laser Beam Welding}

The technology for laser welding has existed for some time but until recent refinement was deemed unsuitable for use in the assembly of thin sheet aluminium due to the magnitude of induced distortions. The lasers used are generally of two forms, either solid state or gaseous. Solid state technology is used in the current experimental work, were the laser beam is produced by stimulating the emission of electromagnetic radiation in a ruby and neodymium-doped yttrium aluminium garnet (Nd:YAG) rod. The alternative gaseous technology employs helium, neon or carbon dioxide as the basis for beam production [11] but ultimately produces the same residual process effects in the final assembled part. 


\subsection{Local material property degradation}

During welding the material within the local region of the joint is exposed to significant temperatures and this alters the microstructure and hence the strength properties of the material. This region, referred to as the Heat Affected Zone (HAZ) is defined by a distance ' $Z$ ' from the weld centre line [12], outside which the original parent material properties are found. When calculating the strength of the assembled structure consideration of the altered properties in the HAZ is required. One method previously examined for aircraft panels [13-14] treats the welded assembly as an integral structure, modifying the structural geometry within the HAZ to account for the modified material properties. This method employs the use of a constant factor ' $\mathrm{K}$ ' which is used to reduce the thickness of the web and flange geometry within the HAZ, as illustrated in Figure 2. The factor is calculated as the ratio of the average HAZ material yield stress to the parent material yield stress. The parent material properties can then be applied to the reduced cross-section and a typical strength analysis performed.

This approach has the necessary computational efficiency required for initial sizing and has already been demonstrated for the strength analysis of single stiffener LBW and Friction Stir Welded (FSW) panels [15]. Therefore this approach to account for local material property degradation will be assessed against experimental data, and if found serviceable will be included within the proposed initial sizing method. 


\subsection{Residual stresses}

Post-welding residual stresses are a result of high transient thermal strains in the weld region caused by local temperature changes during welding. When heat is applied during the welding process compressive stresses are induced in the surrounding material due to thermal expansion. When the joint is formed and the cooling begins, the contraction of the local metal is resisted by the surrounding material creating a zone of tensile residual stresses. The size and magnitude of the tensile zone is directly linked to the magnitude of the energy input used in welding, and with the residual stress system initially in equilibrium (before any resulting distortions are formed) the accompanying compression stresses are also directly linked to the tensile stress state.

When examining the performance of the fabricated panel the inclusion of the tensile stress state is particularly important when considering both damage tolerance and fatigue performance [16], and when additionally analysing the buckling behaviour consideration of the compressive stress state is crucial [17]. For initial aircraft stiffened panel sizing static strength is considered along with basic tensile stress limits to ensure damage tolerance and fatigue requirements are met. Thus, herein, the focus is on assessing the impact of compressive residual stresses on panel skin buckling performance. One method documented by Paik [18] and developed for marine structures uses a modification to the classic buckling stability equation (Equation 1) by making an allowance for the residual stress and is given in Equation 8. The compressive buckling stress of the plate with residual stress, $\sigma_{\mathrm{bc}}$ is then the standard plate buckling stress, given by Equation 1, minus a calculated compression residual stress, $\sigma_{\text {re. }}$ The residual stress is calculated in Equation 9 and is based on a classic fusion welding induced longitudinal residual stress pattern, where $\sigma_{\mathrm{rt}}$ is the tensile 
residual stress peak magnitude; $\sigma_{\mathrm{rc}}$ is the compressive residual stress peak magnitude; $b_{t}$ is the width of the tensile residual stress zone; and $b$ is the total width of the plate.

$$
\begin{array}{ll}
\sigma_{\mathrm{bc}}=\frac{\mathrm{k} \pi^{2} \mathrm{E}_{\mathrm{t}}}{12\left(1-\mathrm{v}^{2}\right)}\left(\frac{\mathrm{t}}{\mathrm{b}}\right)^{2}-\sigma_{\mathrm{re}} & \text { Equation } 8 \\
\sigma_{\mathrm{re}}=\sigma_{\mathrm{rc}}+\frac{2}{\mathrm{~b}}\left(\sigma_{\mathrm{rt}}-\sigma_{\mathrm{rc}}\right)\left(\mathrm{b}_{\mathrm{t}}-\sin \frac{2 \pi \mathrm{b}_{\mathrm{t}}}{\mathrm{b}}\right) & \text { Equation 9 }
\end{array}
$$

This technique for inclusion of welding induced residual stress is computationally appropriate for initial sizing and a simple modification to the current aerospace sizing method. However the approach requires experimental validation as no previous literature is available to verify its use with LBW and panel geometry representative of aircraft components. Paik's approach to account for residual stresses will be assessed against experimental data, and if found serviceable will be included within the sizing method under development.

\subsection{Initial distortions}

Welding residual stresses typically induce distortions in three general forms:

transverse shrinkage perpendicular to the weld line; longitudinal shrinkage parallel to the weld line; and angular distortion (rotation around the weld line). There are methods of overcoming distortion through geometric design, through preventative measures during fabrication and corrective measures after manufacture [6, 19-20]. Thus the ultimate form and magnitude of welding induced distortions is dependent on 
the welding parameters, the materials used, the geometric design of the panel being assembled and any preventative or corrective measures. Therefore a study is required in order to assess the magnitude and impact of distortions for the focused application, allowing the selection of the most appropriate idealisations for initial sizing. To achieve this detailed distortion measurements are required from representative panels. This data may then be used within detailed FE analysis studies to rank the forms of distortion critical to static strength performance. It is worth noting at this point that the impact of distortions on the ultimate static strength of stiffened panels is well understood and it is possible to account for post-buckling stiffener column eccentricity within the conventional collapse analysis, as documented within Section 2.3 .

\subsection{Fatigue and damage tolerance}

The reduction of fatigue and damage tolerance properties in welded structure is directly related to the reduction in parts and the introduction of tensile residual stresses. However, as noted before the fatigue and damage tolerance performance is not examined in detail but considered through the application of working stress limits and geometric design practice and constraints. Therefore modification to the conventional panel sizing procedure to account for fatigue and damage tolerance is not examined herein.

\subsection{Summary}

LBW has been in existence for many years but it is only in recent times that it has been suitably developed for use in the joining of thin aluminium aircraft stiffened 
panels. Three key process effects have been identified for detailed examination and potential inclusion within the sizing method under development. The three effects (material property degradation, induced residual stresses and resultant distortions) will be examined through coupled experimental and FE analysis in the following sections.

\subsection{Experimental validation}

The experimental work has three objectives, first to generate data on the magnitude of representative thin-walled LBW welding process effects. Second, to form the focus for the detailed FE simulation studies which aim to determine the most significant welding residual effects. Third, the experimental data will be used to validate the proposed conventional analysis modifications.

A generic panel configuration representing the fuselage structure of a mid-sized civil transport aircraft formed the central focus of the experimental work. The detailed panel design represents compression critical structure, that is to say, the design is primarily driven by the requirement to carry significant airframe compressive loading. A series of panel specimens representing the fuselage design were manufactured for compression testing. Along with the panel compression specimens a number of supplementary test coupons were also prepared to generate data on specimen material properties, weld HAZ dimensions and residual stresses. All specimen manufacture, including welding fabrication, was undertaken by Constellium in their research facility at CRV and Neuhausen. 


\subsection{Panel compression specimens}

Two compression specimens were manufactured (PCS-1 and PCS-2), illustrated in Figure 3, each consisting of a flat skin (AA 6156) stiffened with three longitudinal Lsection stiffeners (AA 6056), each welded to the skin on a locally thickened skin pad. The welds were performed with all material in the T4 temper and the assembled specimens were then post-weld heat treated to a T6 temper. End-support bases $60 \mathrm{~mm}$ in height were then cast on to each specimen loading end, allowing simultaneously the uniform compression loading of the specimen and clamped loading edge boundary conditions. Once the end-supports were attached the specimens underwent a geometric imperfection scan to measure the specimen distortion. Strain gauges were bonded to the skin and stiffener surfaces at strategic locations to aid in the identification of specimen buckling and post-buckling behaviour. The final stage in preparation of the specimens was to apply a high contrast speckled pattern to the specimen skin surface to allow a Digital Image Correlation (DIC) system to capture full-field skin deformation. The specimens were tested to failure using a $300 \mathrm{kN}$ hydraulic testing machine. The test was carried out by applying the compression load monotonically at a rate of approximately $0.5 \mathrm{~mm}$ per minute until specimen collapse.

\subsection{Specimen geometric properties}

The measurement of the specimens was performed using a Coordinate Measurement Machine (CMM). Figure 4 presents typical stiffener out-of-plane distortion data, with the data plotted in individual planes passing through points at the top and bottom of the particular stiffener element. This data highlights the consistent nature of curvature 
along the length of the stiffeners and the relative alignment/orientation of the stiffeners to the skin pads. The measured data indicates that the form and magnitude of distortion is consistent, with the web out-of-plane distortion considerably smaller than that seen along the stiffener skin and flange. Typically all out-of-plane distortions demonstrate a half sine wave pattern and thus superimposed on each scan line in Figure 4 is a sine curve, fitted using the method of least squares.

\subsection{Parent material properties}

To determine the material properties of the parent materials, compressive tests were performed on coupons which originated from the same material batches as the panel compression specimen components and experienced identical tempering processes. The tests were preformed in accordance with the ASTM compressive material testing standards [21]. Post test the captured material property data was fitted with the Ramberg-Osgood parameters [7] thus enabling its use with the sizing methods outlined in Section 3.

\subsection{HAZ properties}

A series of weld cross-section coupons, sectioned from a full panel compression specimen were prepared for micro hardness mapping. Figure 5 presents typical weld cross-section results. Examining the hardness data there is typically a relatively small softened material zone around each weld centre line. Within and around this zone, there are exhibited relatively gentle gradients in material hardness properties. The reductions in material hardness from parent material properties to the centre of the softened zone are of a magnitude of 20 to $30 \mathrm{Hv}$ (Vickers Hardness). Beyond the 
locally softened zone there is little reduction of skin or stiffener parent material hardness properties. Using the generated hardness data and semi-empirical models, similar to those developed by Myhr \& Grong [22], the average weld joint material properties $(\mathrm{z}$ and $\mathrm{K})$ are calculated for use with the sizing methods outlined in Section 3.

\subsection{Residual stress properties}

In order to understand the residual stress magnitudes that are present within the compression specimens a series of residual stress measurements via hole-drilling were performed on PCS-2. This method was adopted as it is semi-destructive, allowing measurements on a compression test specimen. A small number of 'Uniform Stress Method' [23] measurements were performed within the specimen skin bays; with the specimen in its final test condition. A peak longitudinal compressive residual stress of $30 \mathrm{MPa}$ and an average stress of $22 \mathrm{MPa}$ were measured.

\subsection{Finite Element Analysis}

To determine the most significant process effects and in particular to assess the impact of geometric distortions a series of FE analysis, based on the experimental panel tests has been performed. First, a baseline simulation including the experimentally determined welding process effects was created and validated. The process effects were then systematically varied within the simulation using a Design Of Experiment 
(DOE) approach allowing the assessment of effect impact on predicted static strength. Following this a series of geometric imperfection parametric studies were completed.

\subsection{Baseline simulation}

The idealisation approach adopted represents the stiffener web and flange components along with the specimen skin as an assemblage of shell elements. This approach is essential to enable both the local and global buckling modes of the structure to be simulated [24]. To enable element selection a series of mesh convergence studies were undertaken. The buckling behaviour of uniformly compressed rectangular plates with geometries and boundary conditions designed to replicate those of the specimen's individual plate units were carried out. Each analysis set was developed such that a verifying theoretical buckling calculation could be preformed [25]. Based on these analyses a first-order curved quadrilateral 4-noded finite strain generalpurpose shell elements was selected [26], along with an element mesh density of the order of $3 \mathrm{~mm}$.

Compressive parent material properties obtained from the coupon tests were used to model the skin and stiffener material. The non-linear material data was incorporated into the analysis using the 'classical metal plasticity' constitutive theory [26]. In order to model the material degradation in the specimen HAZ the local model material properties were adjusted to represent the experimentally determined HAZ stress-strain data. 
A stress free geometric imperfection based on the form and magnitude of PCS-1's measured geometric imperfection was applied to the model. PCS-1's imperfection data was selected has it represents the smaller of the two imperfection profiles and thus is more representative of imperfection magnitudes permitted within airframe manufacture. In addition a residual stress state based on the form and magnitude of the PCS-2's measured residual stresses was introduced to the model. The residual stress state was idealised as an initially uniform tensile zone at the weld joint and an initially uniform equalising compression zone elsewhere within the model.

Having created the imperfect model the loads and boundary conditions were applied, which were designed to be as representative of the experimental test setup as possible. A uniform displacement loading was applied to all skin and stiffener nodes at the bottom edges of the model in the panel longitudinal direction. To react this loading, all skin and stiffener edge nodes at the top of the model, were restrained in the displacement loading direction. To represent the specimen cast end-supports all nodes within the cast regions (including the top and bottom edges of the specimen) were constrained against local skin, web or flange out-of-plane displacements. Nodes at the lateral model edges, in regions not cast in end-supports in the test setup, were left unconstrained, again aiming to accurately represent the experimental arrangement. Finally, a non-linear geometric and material FE analysis was performed using the incremental-iterative Newton-Raphson solution procedure [27]. 


\subsection{Simulation validation}

The experimental results, the initial stiffness and the post-buckling stiffnesses of both specimens are very similar until the onset of final collapse behaviour as is seen in Figure 6, where small deviations become evident late on in the post buckling regime. The simulation predicted initial stiffness correlates well with the experimental data and there is only a minor difference between the predicted and measured postbuckling stiffnesses, confined to the final panel behaviour.

With regards initial skin buckling, Table 1, significant scatter is seen within the experimental behaviour ( 17 to $21 \%$ depending on which specimen is used as a reference). The baseline simulation marginally under-predicts the load to cause skin buckling for PCS-1 (2\%), but if compared with PCS-2 the under-prediction rises to $19 \%$.

It is seen that the experimental collapse behaviour results exhibit a significantly lower level of scatter than that found for initial skin buckling. The simulation predicted the collapse mode of PCS-1 along with an accompanying predicted load within $2 \%$ of the measured test load. Of worthy note at this stage is the two different experimental collapse modes: PCS-1 failed with combined stiffener global flexure, inducing additional bending compression stresses on the skin side of the specimen, and local skin yield, see Figure 7. Where as PCS-2 failed with combined stiffener global flexure, however this time flexing in the opposite direction and inducing additional bending compression stresses on the stiffener side of the specimen, and local free flange instability, as illustrated in Figure 7. 
As the simulation represents the form and magnitude of PCS-1's measured geometric imperfection and PCS-2's measured residual stress state careful consideration must be applied when comparing the predictions with the experimental data. The prediction in general is closer to the measured performance and behaviour of PCS-1, suggesting the geometric imperfection is a more dominant welding process effect. However PCS-1's measured geometric imperfection is on average about a third of the magnitude of PCS-2's measured geometric imperfection. With regards residual stress, this was only measured for PCS-2 and thus the relative relationship in terms of form and magnitude between the specimens is unknown. Nevertheless, in general the accuracy of the simulation prediction is very high and the modelling approach thus appropriate for further analysis on the influence of the residual welding process effects.

\subsection{Welding process residual effect ranking}

Using the validated baseline simulation a Taguchi analysis [28] to rank the process effects is first undertaken. Five effects were considered and an L8 array [28] was selected to study the effects at two levels, representing realistic effect magnitude boundaries. Table 2 outlines the studied effects along with the considered magnitude boundaries. Given the theoretical impact of geometric imperfections on plate and column stability performance and based on analysis of the specimen measured imperfections, Section 4.2, the initial geometric imperfections are divided into two key constituents; panel level geometric imperfections (representing a single out-ofplane half wave along the length of the specimen, and characterised by a central peak magnitude, $\delta_{\text {stiffener }}$ ) and local skin bay geometric imperfections (representing a single 
out-of-plane half wave across the width and along the length of each skin bay, characterised by a central peak magnitude, $\left.\delta_{\text {skin }}\right)$. Moreover, within the initial DOE analysis the imperfection boundaries are defined as equal magnitude but positive and negative in direction to cover the full range of potential imperfections, as shown in Table 2.

Based on the simulation combination defined by the L8 array a total of 8 simulations were undertaken. Statistical analyses, ANalysis Of Means (ANOM) and ANalysis Of VAriance (ANOVA), were then preformed on the predicted initial skin buckling load results and the ultimate collapse load results. The ANOM allows the identification of effect interactions within the range of effect magnitude studied. The ANOVA allows the influence of each effect to be numerically characterised.

Based on the ANOM results little or no interaction was found between the five effects studied. Table 3 presents the ANOVA results. Over the range of effect magnitude studied, the skin bay compression residual stress is seen to have a significant influence on initial skin buckling performance ( $75 \%$ of the influence on the response). With regards to collapse, the HAZ material degradation and HAZ material width have a significant influence ( $90 \%$ in total). Finally, over the range of effects studied, both geometric imperfections appear to have only a modest influence on skin buckling and the collapse performance. As a Taguchi analysis focuses on effect boundaries it is considered prudent to further expand our analysis to parametrically consider influence between these effect extremities, and in particular consider in more detail the influence of geometric imperfections. 


\subsection{Geometric imperfection parametric studies}

The first study considered the influence of local skin bay geometric imperfections and the second considered the influence of panel level geometric imperfections. The studied imperfection magnitude ranges were based on the experimental measurements, and the studies continue to use the validated baseline simulation and the same geometric imperfection definitions used within the DOE analysis. During the parametric studies the other welding process effects were set to represent the available experimental measurements. While one geometric imperfection was parametrically varied the other geometric imperfection was set to a fixed magnitude, representing the experimental measurements of PCS-1.

Figure 8 presents the results of the local skin imperfection parametric studies, with simulation predicted initial skin buckling and collapse performance plotted against the magnitude of the modelled geometric imperfection. Considering first initial skin buckling performance, there is no observable impact on load when the imperfection is increased in the negative direction. However, increasing the magnitude of the imperfection in the positive direction generates a steady linear increase in load to cause buckling (approximately $15 \mathrm{kN}$ per millimetre increase in imperfection magnitude). There is no clear change in the form of the buckling modes, Figure 8, and this increase in performance may relate to the increased stability demonstrated by curved plates over flat plates. Considering the collapse behaviour, there is no observed impact on performance over the examined imperfection range. 
Figure 9 presents the results of the panel level imperfection parametric studies. There is no observable impact on initial skin buckling load when the magnitude of imperfection is increased with either a positive or negative direction. Considering the collapse behaviour, there is clear impact on performance when varying the magnitude of the imperfection. In the range $-0.4 \mathrm{~mm}$ to $+0.5 \mathrm{~mm}$ the collapse load increases linearly (approximately $12 \mathrm{kN}$ per millimetre), and from $+0.5 \mathrm{~mm}$ to $+1 \mathrm{~mm}$ the collapse performance decreases linearly (approximately $14 \mathrm{kN}$ per millimetre).

Examining the predicted collapse modes, it is evident that the change in performance, and change in slope in Figure 9, is linked to the direction of flexure during collapse. Between $-0.4 \mathrm{~mm}$ to $+0.5 \mathrm{~mm}$ the simulations predict failure by combined stiffener global flexure, inducing additional bending compression stresses on the stiffener side of the specimen, and local free flange instability. Where as between $+0.5 \mathrm{~mm}$ to +1 $\mathrm{mm}$ the simulations predict failure by combined stiffener global flexure, however this time flexing in the opposite direction and inducing additional bending compression stresses on the skin side of the specimen, and local skin yield.

Finally, considering both initial skin buckling and specimen collapse behaviour, Figure 8 and 9 includes the experimental performance of PCS-1 and -2 , and in all cases, good correlation is evident between the simulation results and the experimental values.

\subsection{Summary}

In summary it is clear that the studied welding process effects, with representative magnitudes based on thin-walled aerospace stiffened panels assembled via LBW, can 
influence static strength performance. Initial skin buckling performance is influenced by the state of skin compressive residual stress and to a lesser extent local skin bay geometric imperfections. However the skin bay imperfections demonstrated a stabilising effect but as imperfections are naturally variable a conservative approach is to exclude such potential influence from initial sizing. With regards to panel collapse behaviour, the computational analysis has demonstrated the potentially significant influence of the HAZ material degradation and panel level geometric imperfections, thus indicating these effects along with the skin compressive residual stress state should be included within initial sizing analysis.

\subsection{Proposed sizing procedure}

Based on the coupled experimental and computational results of Sections 4 and 5, respectively, and using the methods uncovered in the preceding literature, presented in Section 3, this section outlines the proposed modifications to the conventional panel sizing procedure. Figure 10 presents a flowchart of the modified sizing procedure - as the experimental and computational work has demonstrated that local material property degradation, skin bay compression residual stress and panel level geometric imperfections can influence static strength performance, each of these welding process effects is thus incorporated into the sizing calculations.

In order to evaluate and use the proposed analysis procedure, an automated sizing tool for preliminary structural design was created with the functionality to evaluate the 
performance of an individually specified panel design, or size a series of panel designs for a range of loading conditions. Having created the tool it was then used to predict the performance of the experimental specimens. In each case the sizing analysis considered the experimentally measured welding effect magnitudes available for each specimen. Table 4 presents the predicted specimen loads and modes along with the considered welding effect magnitudes.

\subsection{Initial skin buckling behaviour}

Examining initial buckling, the load is under predicted for both specimens, in the case of PCS- 1 by $1.6 \%$ and in the case of PCS-2 by $18.4 \%$. The level of prediction conservatism demonstrated by PCS-2 may potentially relate to the impact of ignoring the stabilising influence of positive direction local skin imperfections. However, as stated previously such stabilising imperfections may not be guaranteed and thus should not be considered in initial sizing. Also it is important to note that the residual stress magnitude used in the analysis of both specimens was based on measurements from PCS-2, thus the similarity between the predicted buckling load of PCS-1 and the experimentally measured load should not be interpreted as validating a high degree of prediction method accuracy.

\subsection{Collapse behaviour}

The predicted load to cause the key collapse modes are also given in Table 4 . The predicted loads are in good agreement with the experimental loads. Comparing equivalent modes, the predicted collapse load for PCS- 1 is $0.8 \%$ lower than that experimentally measured, and for PCS-2 it is 9.3\% lower than that experimentally 
measured. It is worth noting that combined stiffener global flexure and local free flange was the failure mode predicted for PCS-1 rather than the experimentally observed mode of combined stiffener global flexure and local skin yield.

\subsection{Summary}

In summary the predicted panel performance can be considered accurate and demonstrates an appropriate level of conservatism when individual measured process effects are used as analysis input. Considering industrial application, the definition of the welding process effect magnitudes will necessarily need to consider the nondeterministic nature of manufacturing output and thus probabilistic consideration of the welding induced effects or imperfections is required [29-30]. Such consideration is currently accomplished when generating aerospace design allowables (A- and Bbasis properties [31]) and a similar approach may be possible for each of the individual process effects used within the modified sizing procedure.

\subsection{Design studies}

In the light of the preceding analysis it is clear that weld effects influence static strength performance and thus a series of design studies have been undertaken to quantify the impact on panel structural efficiency. The lower fuselage and top skin of the wing are both subjected to significant compression loading and are thus appropriate candidates for study. In each study the developed initial sizing tool is used, with a design space constrained to give realistic manufacturable configurations 
with representative fatigue and damage tolerant local design features. The key difference between the fuselage and wing design constraints other than loading are:

- the minimum acceptable buckling ratio (i.e. initial skin buckling stress / collapse stress), $33.3 \%$ for the fuselage, $86.7 \%$ for the wing.

- the minimum acceptable stiffener pitch, $152.4 \mathrm{~mm}$ for the fuselage and $76.2 \mathrm{~mm}$ for the wing).

- the target stiffening ratio (i.e. stiffener total cross-sectional area / skin total crosssectional area), $29-31 \%$ for the fuselage, $49-51 \%$ for the wing.

Finally, for consistency both the fuselage and wing design spaces are constrained to match the material and stiffener cross-section type of the preceding experimental work.

\subsection{Design study 1 - Inclusion of weld effects}

The first design analysis considers the design of a series of panels assuming zero weld effects. Having sized the panels assuming no weld effects the static performance of each design in the series is then reanalysed assuming a complete complement of effects. In order to clearly illustrate the impact of the welding effects on the performance the magnitude of the effects imposed is of a severe level, as shown in Table 5. Furthermore as the panel designs address a large range of loads and thus local weld joint dimensions the applied weld effect magnitudes also include linkages to the local weld joint geometric dimensions. Figure 11a presents the design study results along with yield design lines which represents panel performance where all 
instability behaviour is controlled and failure is wholly attributed to material yielding. The closer a real panel design line gets to this yield line the higher its efficiency.

Examining the calculated design lines for both applications there is a significant drop in the load intensity when the sized designs are reanalysed assuming the complete complement of weld effects. In the fuselage case the greatest drop in the load intensity is $18.5 \%$ and for the wing designs the greatest drop is $6.8 \%$. With such differences between target and calculated performance it is clearly important to consider the weld effects within the initial sizing process.

Figure $11 \mathrm{~b}$ also presents a further design study line when the weld effects presented in Table 5 are modelled within the initial sizing process. For the fuselage case at the lower load intensities it can be seen that it is possible to create panel designs which match the zero weld effect panel performance. At the higher load intensities there is some requirement for additional panel cross-sectional area to reach the target loads. To illustrate the local cross-sectional changes Figure 12 presents a selection of detailed fuselage design results. These results illustrate a small but consistent thickening of the panel skin to offset the welding induced compressive residual stresses. In addition the stiffener pad and flange geometry grows to increase the bending stiffness of the post buckling column and offset the reduced material properties of the HAZ and the additional eccentricity due to the welding. Examining the wing case it is possible to create panel designs which match the zero weld effect panel performance across the complete loading spectrum with only minor crosssectional area increases required at the highest loading intensities, as illustrated in 
Figure 11. The wing designs appear less sensitive given their greater cross-sectional area and thus any degraded HAZ material represents a smaller percentage of the panel. In addition a combination of more stringent constraints on buckling and greater skin thickness and post buckling column bending stiffness make wing panel designs generally less sensitive to welding induced compressive residual stress and eccentricity.

\subsection{Design study 2 - Weld effect magnitudes}

As the previous study considered a single fixed set of weld induced effects this design study examines the impact of weld effect magnitudes. Table 6 presents a series of four varying weld effect magnitude sets. These represent the output from a highly optimised welding, material and joint design process (Run 1) to a worse case output of an un-optimised panel welding process (Run 4). Unlike the previous design study the weld effect magnitudes are not linked to the panel geometry.

The design study results are plotted in Figure 12. Considering first the fuselage results, for Run 1 and 2 there is little impact on panel efficiency. For Runs 3 and 4 there is a clear deviation from the slope of the zero weld effect design line above load intensities greater than $1,000 \mathrm{kN} / \mathrm{m}$. Considering the wing results, for all runs there is minimal deviation from the slope of the zero weld effect design line. To quantify these results the average panel mass of each run was calculated and the change in mass from the zero weld effect results was expressed in terms of a percentage. Table 6 presents the results of this exercise. Runs 3 and 4 both show an increase in mass for the fuselage, whereas only Run 4 shows a minimal gain in mass for the wing. This 
indicates that weld effects can have minimal impact on panel mass in the majority of cases as long as the welding process is optimised and the key weld effects are considered within the design process.

\subsection{Conclusions}

The aim of this paper was to formulate and validate modifications which can be used with conventional inexpensive panel sizing methods to account for the influence of welding process effects on static strength. To achieve this coupled panel experimental testing and detailed FE simulation of the tests were used to determine the most significant process effects. The combined studies established the need to consider welding induced material property degradation, residual stresses and panel level geometric distortions, as these can reduce static strength performance. A sizing procedure was successfully developed which considers the above welding effects and was validated against experimental panel test results. Finally, the validated sizing procedure was used to conduct a series of fuselage and wing structural design tradestudies establishing that the potential reductions in strength performance may be overcome through local geometric tailoring during initial sizing, thus negating panel weight penalties for the majority of design scenarios.

\section{Acknowledgements}

The authors gratefully acknowledge the technical and financial support of Constellium CRV, Voreppe, France. 


\section{References}

[1] Irving, P., "End of the aircraft rivet-the coming of the welded aircraft". Aerogram, Vol. 10, No. 2, pp. 31-41, September 2001.

[2] Zink, W., "Advanced Aircraft Fuselage Structures". The European Symposium on Assessment of Power Beam Welds. GKSS Research Centre, Geesthact, Germany, 1999.

[3] Tempus, G., "New Aluminium Alloys and Fuselage Structures in Aircraft". Materials Day, Werkstoffe Fur Transport und Verkehr, ETH Zurich, Switzerland, 2001.

[4] Rotzer, I., "Laser-beam welding makes aircraft lighter". Fraunhofer Magazine, Vol. 1, 2005.

[5] Li, Z. and Gobbi, S.L., "Laser welding for lightweight structures". Journal of Materials Processing Technology, Vol. 70(1-3), pp. 137-144, 1997.

[6] Vollertsen, J., et al. "Innovative Welding Strategies for the Manufacture of Large Aircraft". International Conference on Technical Trends and Future Prospectives of Welding Technology for Transportation, Land, Sea, Air and Space, Osaka, Japan, 2004.

[7] Ramberg, W., and Osgood, W.R., "Description of Stress-Strain Curves by Three Parameters". National Advisory Committee of Aeronautics, Washington, USA, 1943.

[8] Bruhn, EF., “Analysis and Design of Flight Vehicle Structures”. 1st Edition, Tri-State Offset Company, 1973. 
[9] Anon., "NASA Astronautics Structures Manual, Vol. 3". NASA, Washington, US, 1961.

[10] Anon., "ESDU Structures sub-series”. Engineering sciences data units, ESDU International Ltd, London, 1965.

[11] Norrish, J., “Advanced Welding Processes - Technologies and Process Control”. Woodhead Publishing Limited, Cambridge, 2006.

[12] Anon., "Structural use of aluminium, part 1: Code of practice for design”. British Standard Institution, BS 8118, 1991.

[13] Gibson, A., and Sterling, S., “A design and test programme involving welded sheetstringer compression panels". $21^{\text {st }}$ International Council of the Aeronautical Sciences Congress, Melbourne, Australia, ICAS-98-7.7.4, 1998.

[14] Lynch, F., Price, M., Murphy, A., Gibson, A., Poston, K. and Moore, G., “Analysis of Weld Configuration for Laser Welded Skin-Stringer Fuselage Sub-Panels in Compression". $4^{\text {th }}$ International Conference on Thin-Walled Structures, Loughborough, England, pp. 145-152, 2004.

[15] Murphy, A., Lynch, F., Price, M and Gibson, A., "Modified stiffened panel analysis methods for laser beam and friction stir welded aircraft panels". Journal of Aerospace Engineering, Vol. 220, G4, pp. 267-278, 2006.

[16] Zhang, X. and Li, Y., "Damage Tolerance and Fail Safety of Welded Aircraft Wing Panels”. AIAA JOURNAL, Vol. 43, No. 7, July 2005 
[17] Murphy, A., Price, M., Curran, R. and Wang, P., "The Integration Of Strength And Process Modeling Of Friction-Stir-Welded Fuselage Panels". AIAA Journal of Aerospace Computing, Information, and Communication, Vol. 3, pp 159-176, 2006.

[18] Paik, J.K. and A.K. Thayamballi, "Ultimate Limit State Design of Steel-Plated Structures". Wiley, London, 2003.

[19] Ivetic, G., A. Lanciotti, and C. Polese, "Electric strain gauge measurement of residual stress in welded panels”. Journal of Strain Analysis, Vol. 44, pp 117-126, 2009.

[20] Masubuchi, K., “Analysis of welded structures”. First ed., Pergamon Press, 1980.

[21] Anon., "Standard test methods of compression testing of metallic material at room temperature". American Society for Testing and Materials, ASTM E9-89a, 1989.

[22] Myhr, O.R. and O.Grong, "Process modelling applied to 6082-T6 aluminium weldments - ii. application of model”. Acta Metallurgica et Materialia, Vol. 39(11), pp. 2703-2708, 1991.

[23] Anon., "Standard Test Method for Determining Residual Stresses by the HoleDrilling Strain-Gage Method". American Society for Testing and Materials, ASTM E837-08, 2008.

[24] Lynch, C., Murphy, A., Price, M., and Gibson, A., "The computational post-buckling analysis of fuselage stiffened panels loaded in compression". Thin-Walled Structures, Vol. 42(10), pp, 1445-64, 2004.

[25] Murphy, A., Price, M., and Gibson, A., "Toward virtual testing of airframe stiffened panels”. Royal Aeronautical Society - Virtual Testing Conference, London, 2006.

[26] Anon., “ABAQUS / Standard user's manual”. Hibbitt, Karlsson and Sorenson, 2010. 
[27] Becker, A.A., "Understanding non-linear finite element analysis - Through illustrative benchmarks". 1 1st edition, NAFEMS (ISBN 1-8743-7635-2), 2001.

[28] Roy, R., “A primer on the Taguchi method”. Society of Manufacturing Engineers, Michigan, USA, 1990.

[29] Stroud, W.J., Krishnamurthy, T., Sykes N.P. and Elishako I., "Effect of Bow-Type Initial Imperfection on Reliability of Minimum-Weight, Stiffened Structural Panels". National Aeronautics and Space Administration, Washington, NASA TP-3263, 1993.

[30] Hilburger, M.W., Nemeth, M.P., and Starnes, J.H., "Shell Buckling Design Criteria Based on Manufacturing Imperfection Signatures”. AIAA Journal, 44, (3), March 2006.

[31] Widener, C., Tweedy, B., and Burford, D., "Path Independence of Allowables Based Friction Stir Butt Welds". 7th AIAA Aviation Technology, Integration and Operations Conference (ATIO), AIAA 2007-7864, Belfast, Northern Ireland, 2007.

[32] Anon., "Polymer Matrix Composites". Military Standardization Handbook, MILHDBK-17-3F, Vol. 3, 2002. 


\section{Table}

Table 1 - Experimental and predicted specimen initial skin buckling and collapse loads.

\begin{tabular}{cccc}
\hline Specimen & PCS-1 & PCS-2 & $\begin{array}{c}\text { Baseline } \\
\text { simulation }\end{array}$ \\
\hline $\begin{array}{c}\text { Initial skin } \\
\text { buckling (kN) }\end{array}$ & 37.0 & 44.6 & 36.1 \\
$\begin{array}{c}\text { Specimen collapse } \\
(\mathrm{kN})\end{array}$ & 210.7 & 201.8 & 206.8 \\
$\begin{array}{c}\text { Initial buckling to } \\
\text { collapse ratio (\%) }\end{array}$ & 18 & 22 & 17 \\
Collapse mode & $\begin{array}{c}\text { Combined } \\
\text { stiffener global } \\
\text { flexure and local } \\
\text { skin yield }\end{array}$ & $\begin{array}{c}\text { Combined stiffener } \\
\text { global flexure and } \\
\text { local free flange } \\
\text { instability }\end{array}$ & $\begin{array}{c}\text { Combined } \\
\text { stiffener global } \\
\text { flexure and local } \\
\text { skin yield }\end{array}$ \\
\hline
\end{tabular}

Table 2 - Initial DOE studied process effects and their studied magnitude boundaries.

\begin{tabular}{|c|c|c|}
\hline Welding process effect & $\begin{array}{l}\text { Lower } \\
\text { boundary }\end{array}$ & $\begin{array}{c}\text { Upper } \\
\text { boundary }\end{array}$ \\
\hline HAZ material degradation $(\mathrm{K})$ & 0.5 & 1.0 \\
\hline HAZ material width $(Z)$ & $6 \mathrm{~mm}$ & $12 \mathrm{~mm}$ \\
\hline Panel level geometric imperfection $\left(\delta_{\text {stiffener }}\right)^{*}$ & $-0.3 \mathrm{~mm}$ & $+0.3 \mathrm{~mm}$ \\
\hline Local skin bay geometric imperfections $\left(\delta_{\text {skin }}\right)^{*}$ & $-0.2 \mathrm{~mm}$ & $+0.2 \mathrm{~mm}$ \\
\hline Skin bay compression residual stress $\left(\sigma_{\text {re }}\right)$ & $15 \mathrm{MPa}$ & $30 \mathrm{MPa}$ \\
\hline \multirow{2}{*}{$\begin{array}{l}* \text { - geometric imperfections are denoted as positive } \\
\text { and negative with regards to the panel geometry }\end{array}$} & १ิ & [ \\
\hline & + & \\
\hline
\end{tabular}


Table 3 - Initial DOE ANOVA results.

\begin{tabular}{lcc}
\hline \multicolumn{1}{c}{ Welding process effect } & $\begin{array}{c}\text { Initial skin } \\
\text { buckling } \\
(\mathrm{kN})\end{array}$ & $\begin{array}{c}\text { Specimen } \\
\text { collapse } \\
(\mathrm{kN})\end{array}$ \\
\hline HAZ material degradation $(\mathrm{K})$ & $6 \%$ & $83 \%$ \\
HAZ material width $(\mathrm{Z})$ & $0 \%$ & $7 \%$ \\
Panel level geometric imperfection $\left(\delta_{\text {stiffener }}\right)$ & $9 \%$ & $3 \%$ \\
$\begin{array}{l}\text { Local skin bay geometric imperfections }\left(\delta_{\text {skin }}\right) \\
\text { Skin bay compression residual stress }\left(\sigma_{\text {re }}\right)\end{array}$ & $10 \%$ & $0 \%$ \\
$\begin{array}{l}\text { Interaction between: } \\
\text { HAZ material } \\
\text { degradation }\end{array}$ & $75 \%$ & $0 \%$ \\
$\begin{array}{l}\text { Panel level geometric } \\
\text { imperfection }\end{array} \quad \& \quad \begin{array}{l}\text { Local skin bay } \\
\text { geometric imperfections }\end{array}$ & $0 \%$ & $7 \%$ \\
\hline
\end{tabular}

Table 4 - Modified conventional sizing method validation.

\begin{tabular}{|c|c|c|}
\hline \multirow[t]{2}{*}{ Specimen } & \multicolumn{2}{|c|}{ Sizing tool predictions } \\
\hline & $\begin{array}{l}\text { Representing } \\
\text { PCS-1 }\end{array}$ & $\begin{array}{l}\text { Representing } \\
\text { PCS-2 }\end{array}$ \\
\hline HAZ material degradation $(\mathrm{K})$ & 0.8 & 0.8 \\
\hline HAZ material width $(Z)$ & $6 \mathrm{~mm}$ & $6 \mathrm{~mm}$ \\
\hline Panel level geometric imperfection $\left(\delta_{\text {stiffener }}\right)$ & $0.3 \mathrm{~mm}$ & $1.0 \mathrm{~mm}$ \\
\hline Skin bay compression residual stress $\left(\sigma_{\mathrm{re}}\right)$ & \multicolumn{2}{|c|}{$\begin{array}{c}30 \mathrm{MPa} \\
\text { (PCS-2 peak measured stress) }\end{array}$} \\
\hline Initial skin buckling (kN) & 36.4 & 36.4 \\
\hline \multicolumn{3}{|l|}{ Specimen collapse $(\mathrm{kN})$} \\
\hline $\begin{array}{l}\text { via combined stiffener global flexure and } \\
\text { local skin yield }(\mathrm{kN})\end{array}$ & 209.1 & 199.5 \\
\hline $\begin{array}{l}\text { via combined stiffener global flexure and } \\
\text { local free flange instability }(\mathrm{kN})\end{array}$ & 207.8 & 183.1 \\
\hline
\end{tabular}


Table 5 - Design study 1 - modelled weld effects.

\begin{tabular}{lc}
\hline \multicolumn{1}{c}{ Welding process effect } & Magnitude \\
\hline HAZ material degradation $(\mathrm{K})$ & 0.6 \\
HAZ material width $(Z)$ & $\mathrm{t}_{\mathrm{web}}$ \\
Panel level geometric imperfection $\left(\delta_{\text {stiffener }}\right)$ & $0.2 \mathrm{t}_{\mathrm{web}}$ \\
Tensile residual stress peak magnitude $\left(\sigma_{\mathrm{rt}}\right)$ & $0.8 \sigma_{\mathrm{cy}}$ \\
Width of the tensile residual stress zone $\left(\mathrm{b}_{\mathrm{t}}\right)$ & $2 \mathrm{t}_{\mathrm{web}}$ \\
Compressive residual stress peak magnitude $\left(\sigma_{\mathrm{rc}}\right)$ & $0.1 \sigma_{\mathrm{cy}}$ \\
\hline
\end{tabular}

Table 6 - Design study 2 - modelled weld effects.

\begin{tabular}{|c|c|c|c|c|}
\hline $\begin{array}{l}\text { Welding } \\
\text { process effect }\end{array}$ & $\mathrm{R}_{1}$ & Run 2 & Run 3 & Run 4 \\
\hline HAZ material degradat & 0.9 & 0.8 & 0.7 & 0.6 \\
\hline HAZ material widtl & $t_{\mathrm{web}}$ & $t_{\text {web }}$ & $t_{\mathrm{web}}$ & $\mathrm{t}_{\mathrm{web}}$ \\
\hline $\begin{array}{l}\text { Panel level geometric } \\
\text { imperfection }\left(\delta_{\text {stiffener }}\right)\end{array}$ & $0.05 \mathrm{t}_{\mathrm{web}}$ & $0.10 \mathrm{t}_{\mathrm{web}}$ & $0.15 \mathrm{t}_{\mathrm{web}}$ & $0.20 \mathrm{t}_{\mathrm{web}}$ \\
\hline $\begin{array}{l}\text { Tensile residual stress peak } \\
\text { magnitude }\left(\sigma_{\mathrm{rt}}\right)\end{array}$ & $0.65 \sigma_{\mathrm{cy}}$ & $0.70 \sigma_{\mathrm{cy}}$ & $0.75 \sigma_{\mathrm{cy}}$ & $0.80 \sigma_{\mathrm{cy}}$ \\
\hline $\begin{array}{l}\text { Width of the tensile residual } \\
\text { stress zone }\left(b_{t}\right)\end{array}$ & $2 t_{\text {web }}$ & $2 t_{\text {web }}$ & $2 t_{\text {web }}$ & $2 t_{\mathrm{web}}$ \\
\hline $\begin{array}{l}\text { Compressive residual stress } \\
\text { peak magnitude }\left(\sigma_{\mathrm{rc}}\right)\end{array}$ & $0.1 \sigma_{\mathrm{cy}}$ & $0.1 \sigma_{\mathrm{cy}}$ & $0.1 \sigma_{\mathrm{cy}}$ & $0.1 \sigma_{\mathrm{cy}}$ \\
\hline
\end{tabular}

Change in panel design mass with respect to the effect zero design:

\begin{tabular}{lcccc}
\hline For total fuselage design range & $0 \%$ & $0 \%$ & $+2.2 \%$ & $+6.2 \%$ \\
For total wing design range & $0 \%$ & $0 \%$ & $0 \%$ & $+0.3 \%$ \\
\hline
\end{tabular}




\section{Figures}

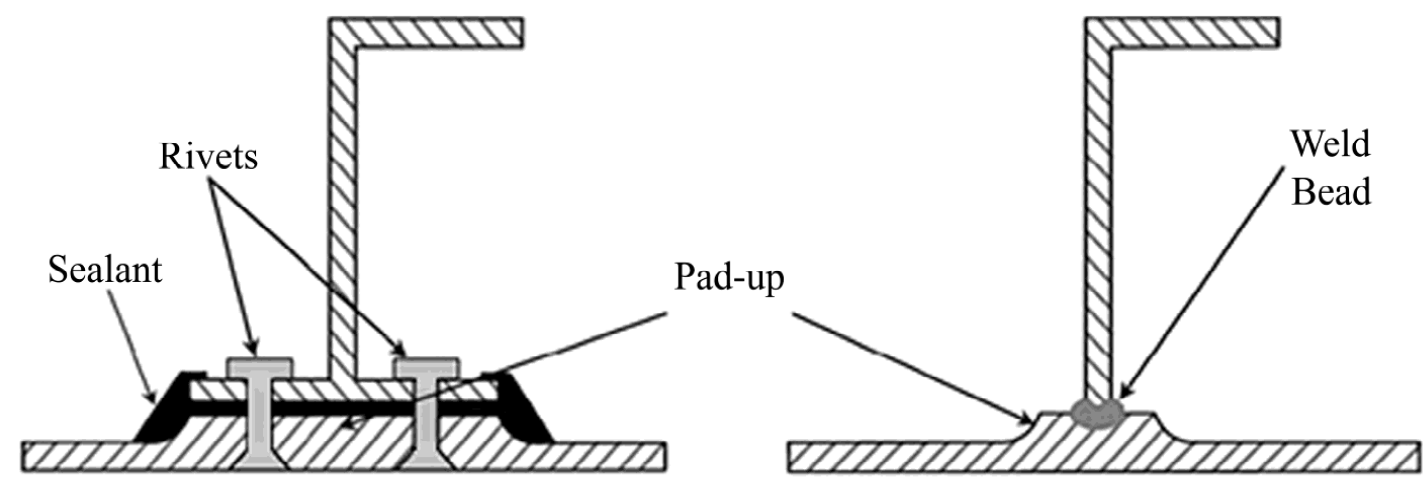

a) Conventional rivet joint with pad-up

b) Typical laser beam welded joint

Figure 1 - Riveted versus Laser Beam Welding stiffened panel joint detail.

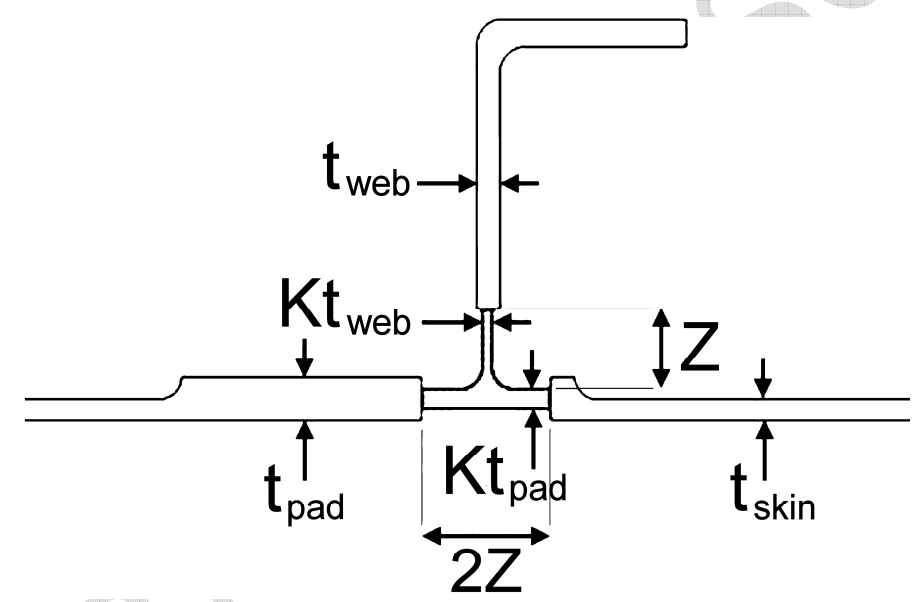

Figure 2 - Cross-section modification to account for local material property degradation. 

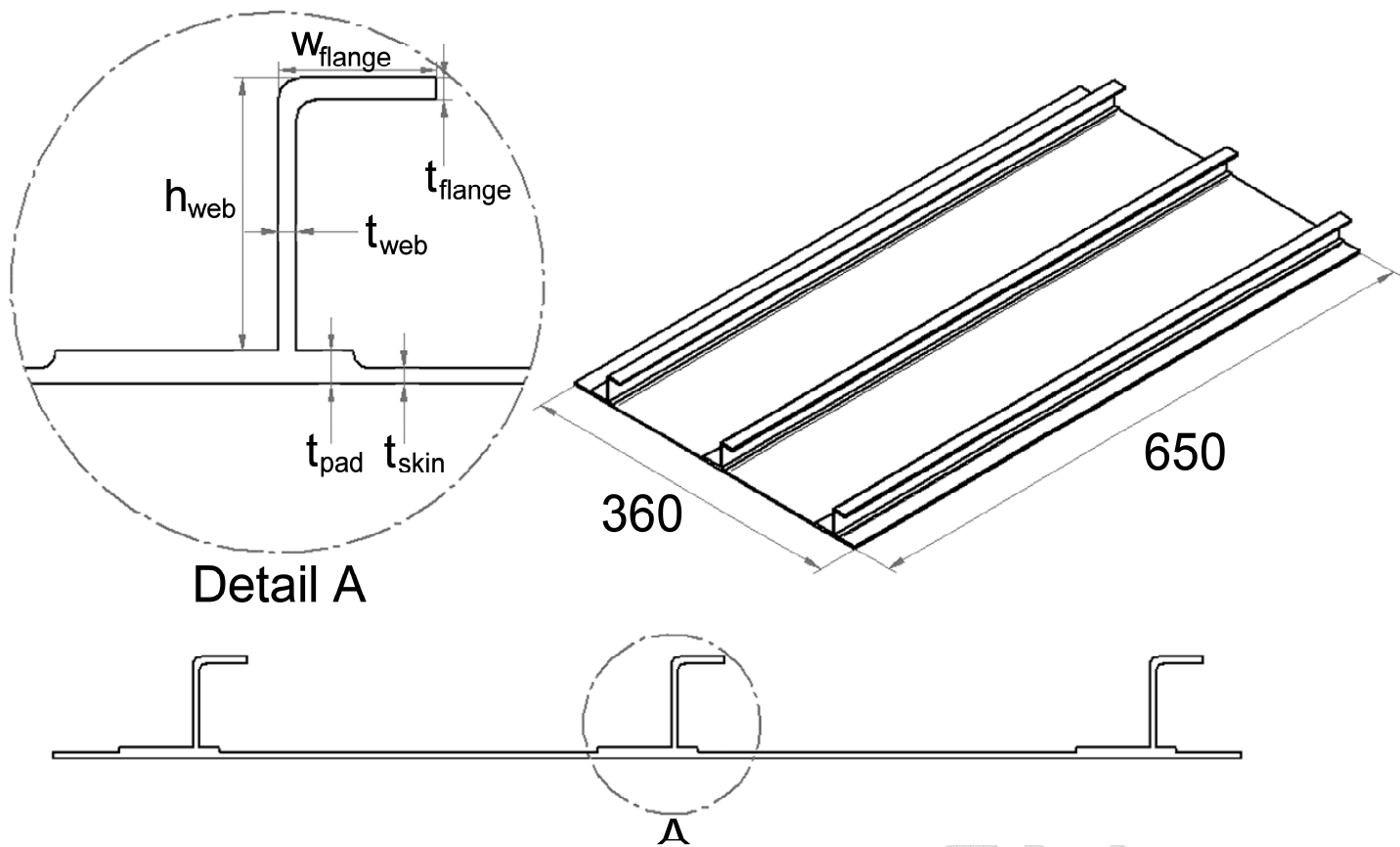

Figure 3 - Compression specimen configuration (all dimensions given in $\mathrm{mm}$ ).

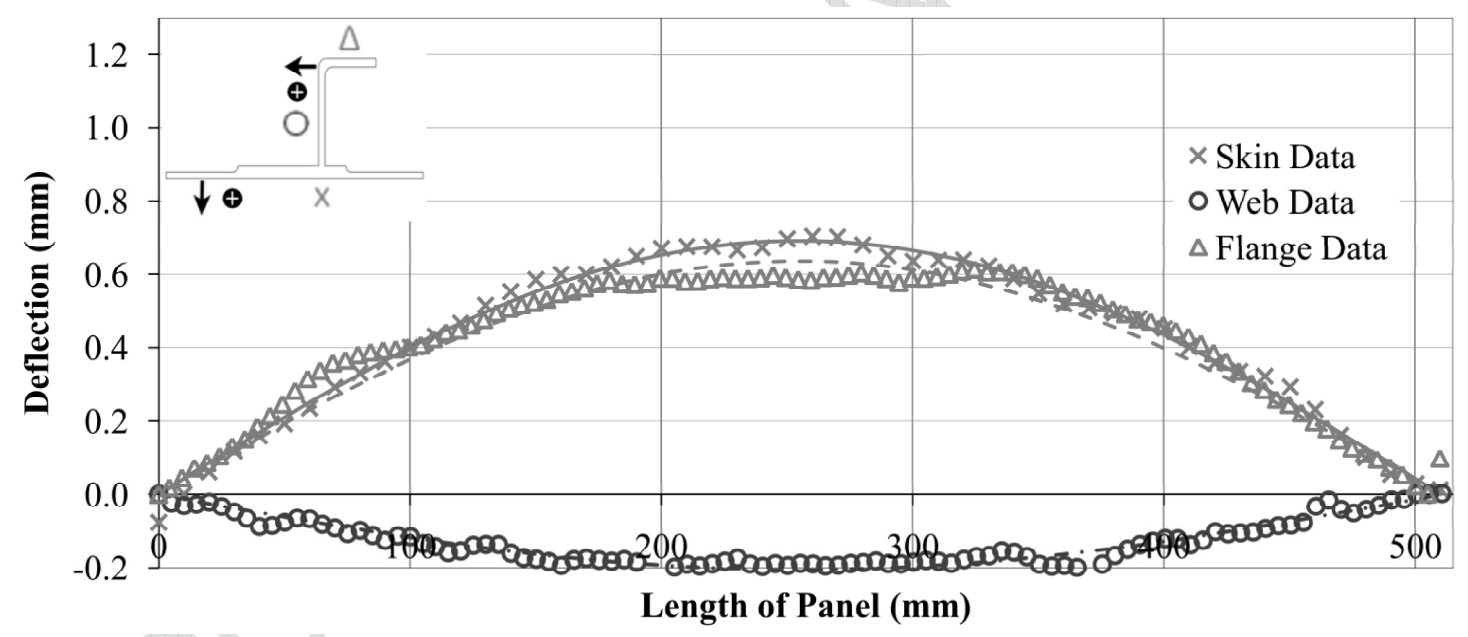

Figure 4 - Typical measured out-of-plane distortion data. 


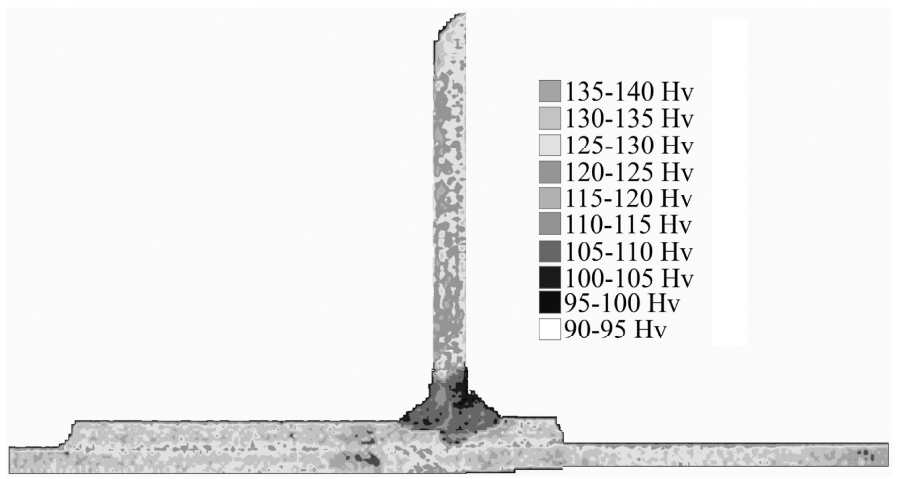

Figure 5 - Typical weld joint micro hardness map.

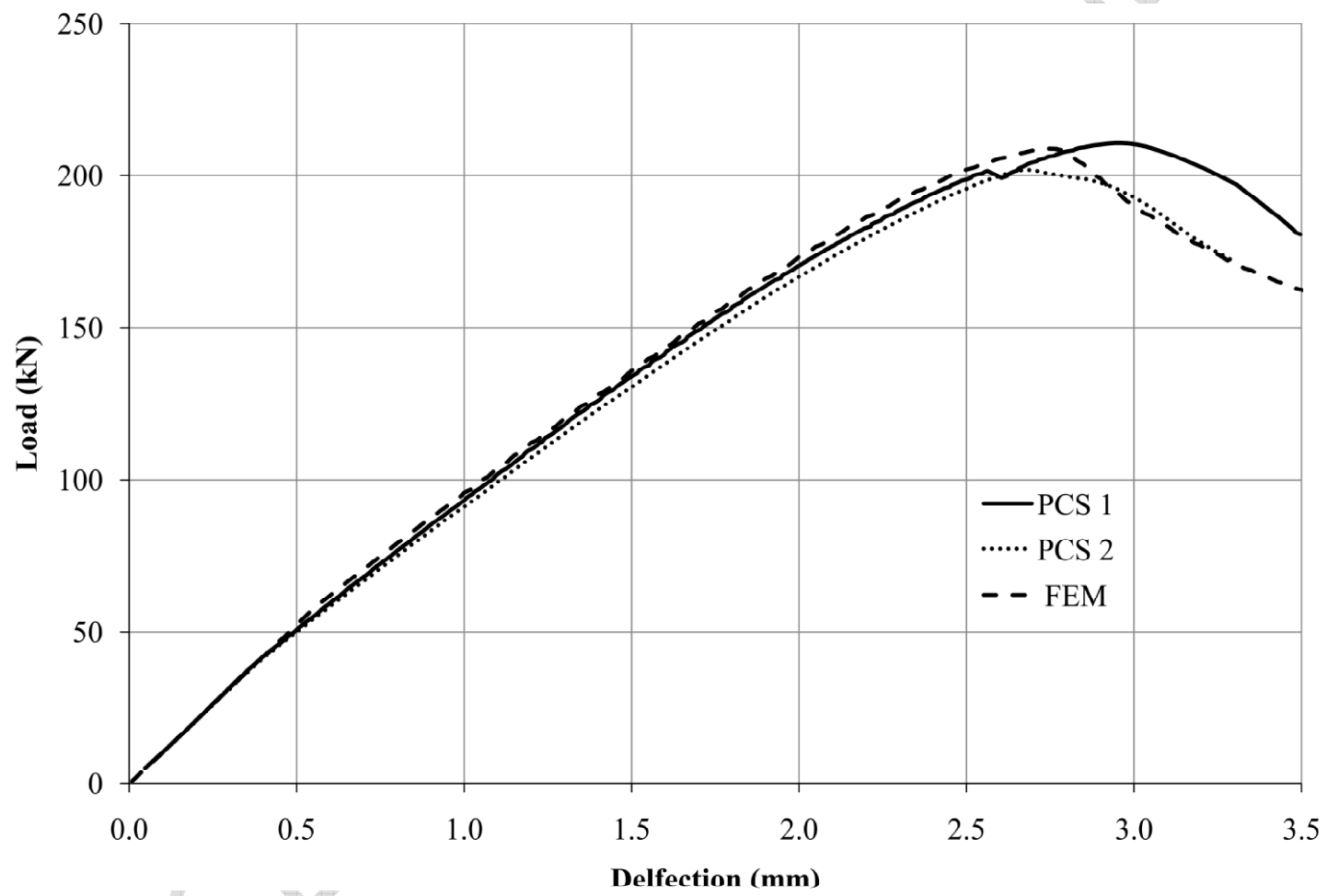

Figure 6 - Experimental and baseline simulation load versus end-shortening curves. 


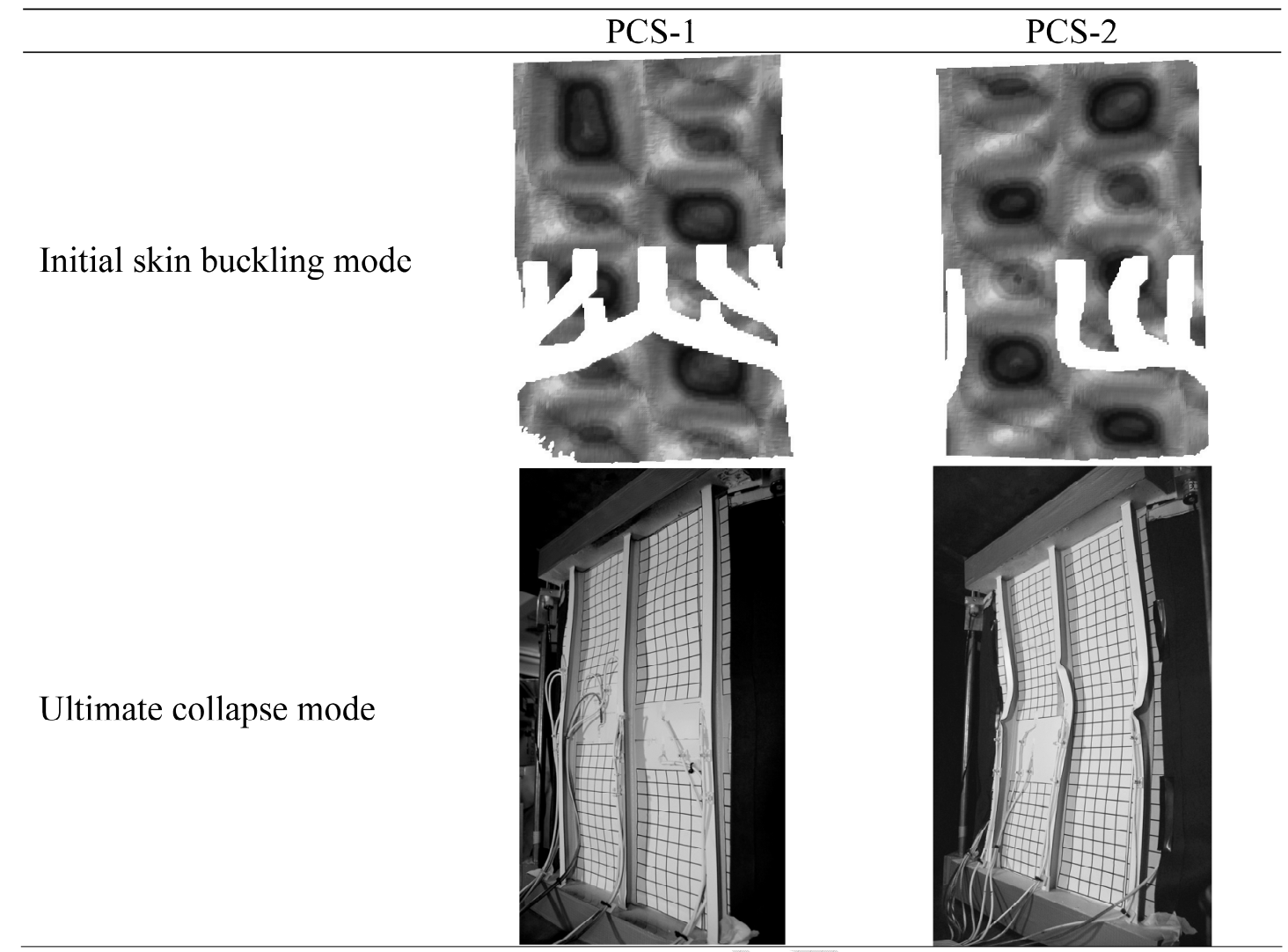

Figure 7 - Observed experimental initial specimen skin buckling and ultimate collapse behaviour. 

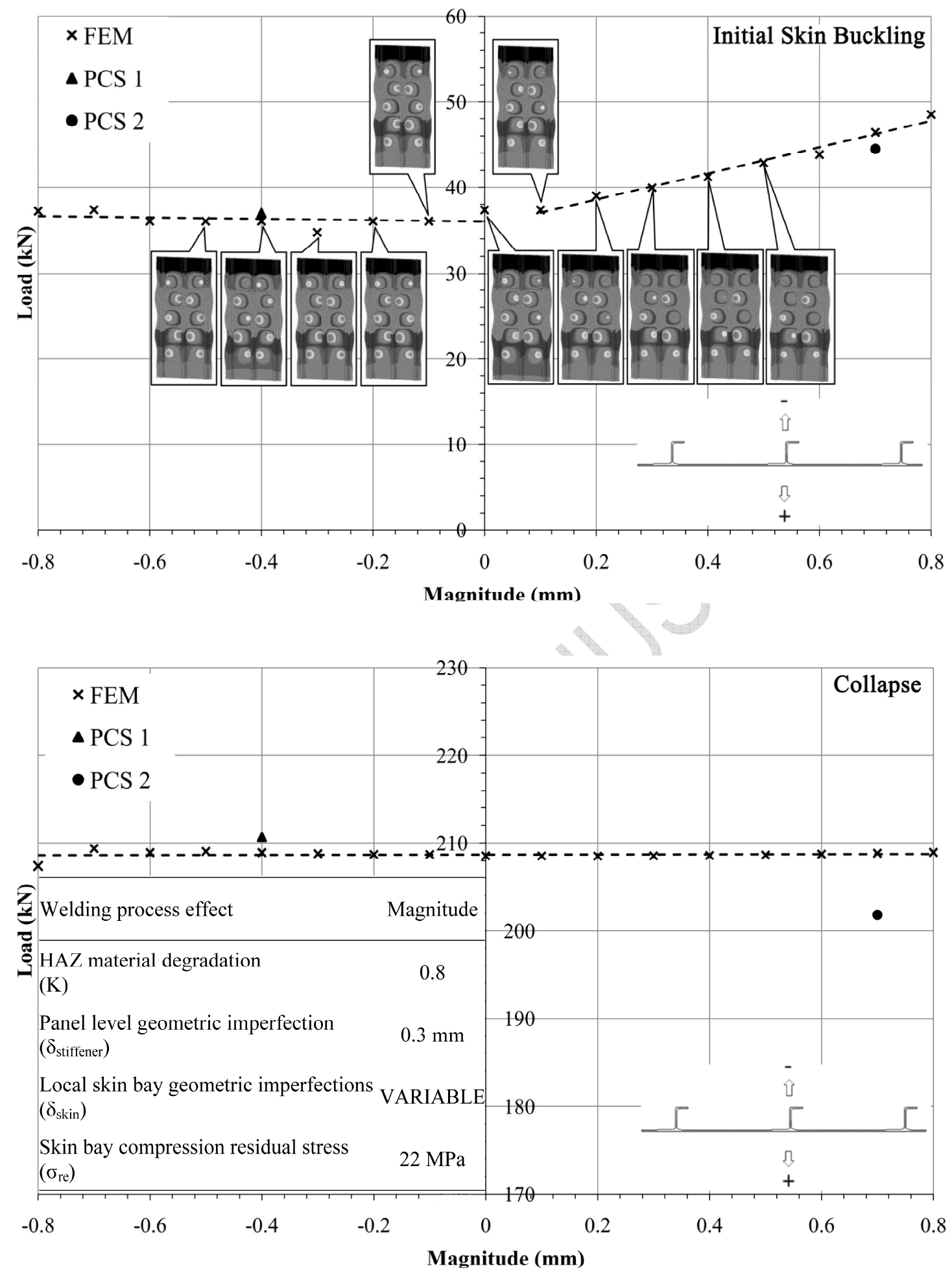

Figure 8 - Specimen longitudinal out-of-plane imperfection parametric study. 

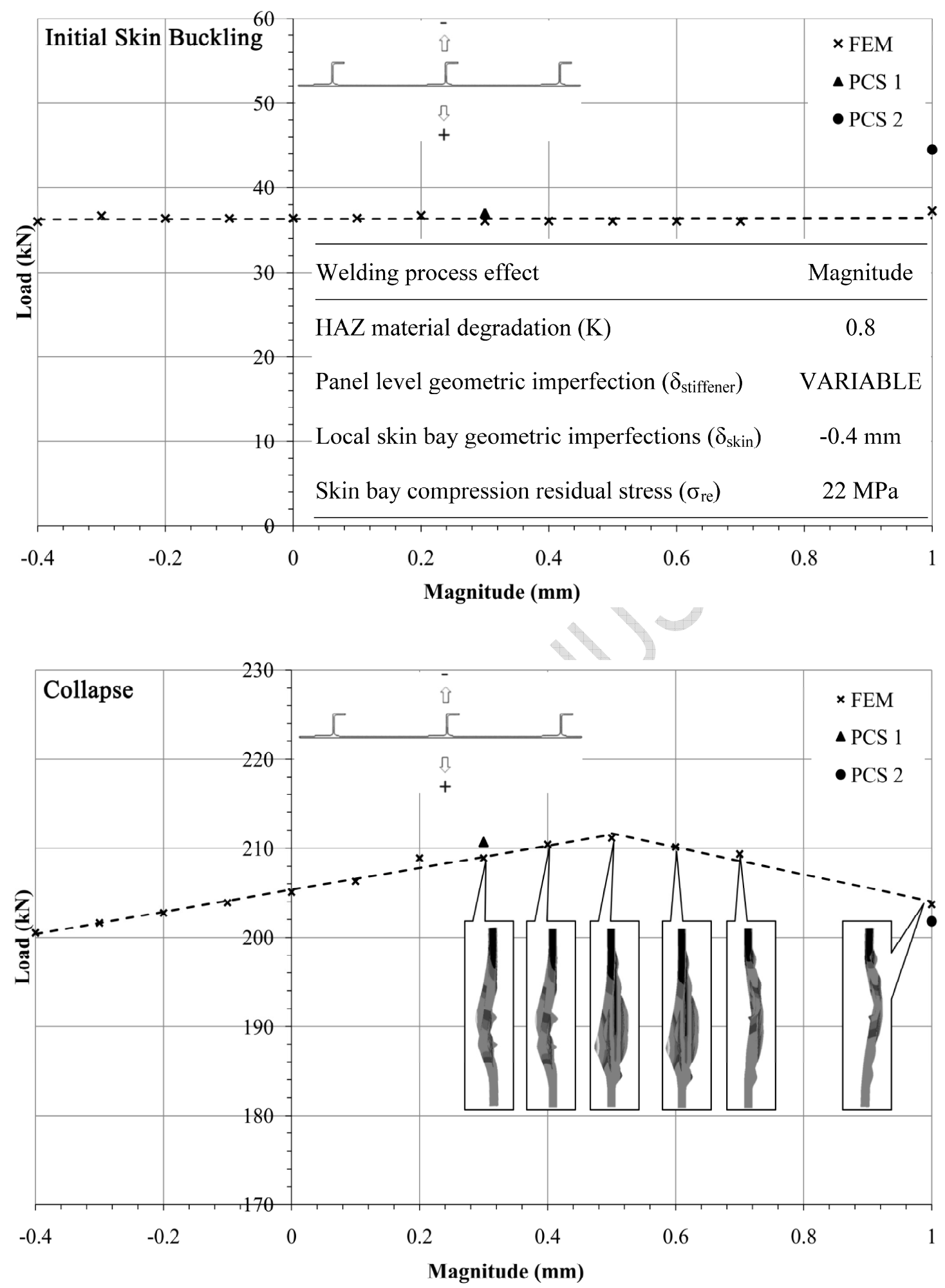

Figure 9 - Skin lateral and longitudinal out-of-plane imperfection parametric study. 


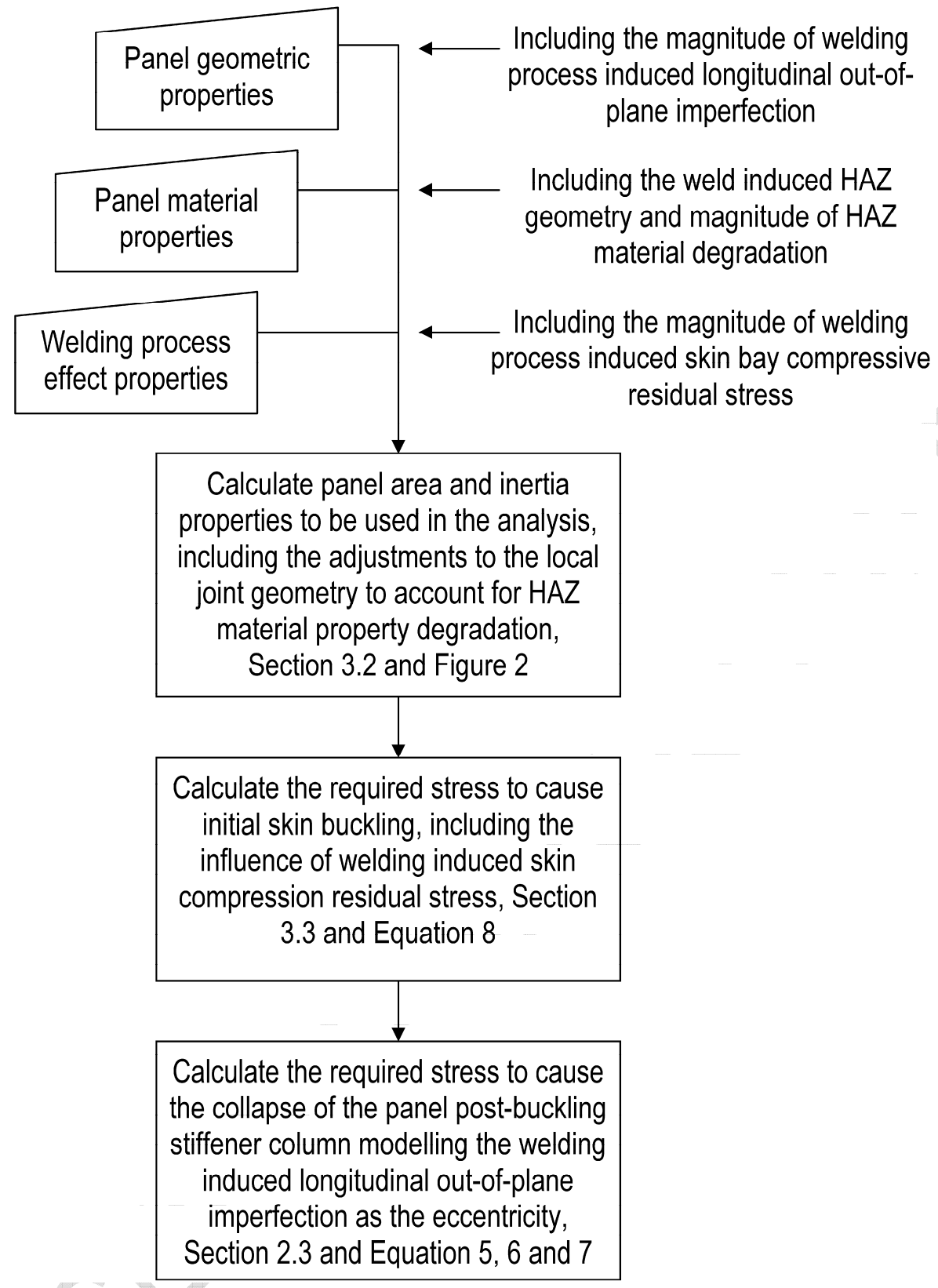

Figure 10 - Flowchart of the proposed sizing procedure. 

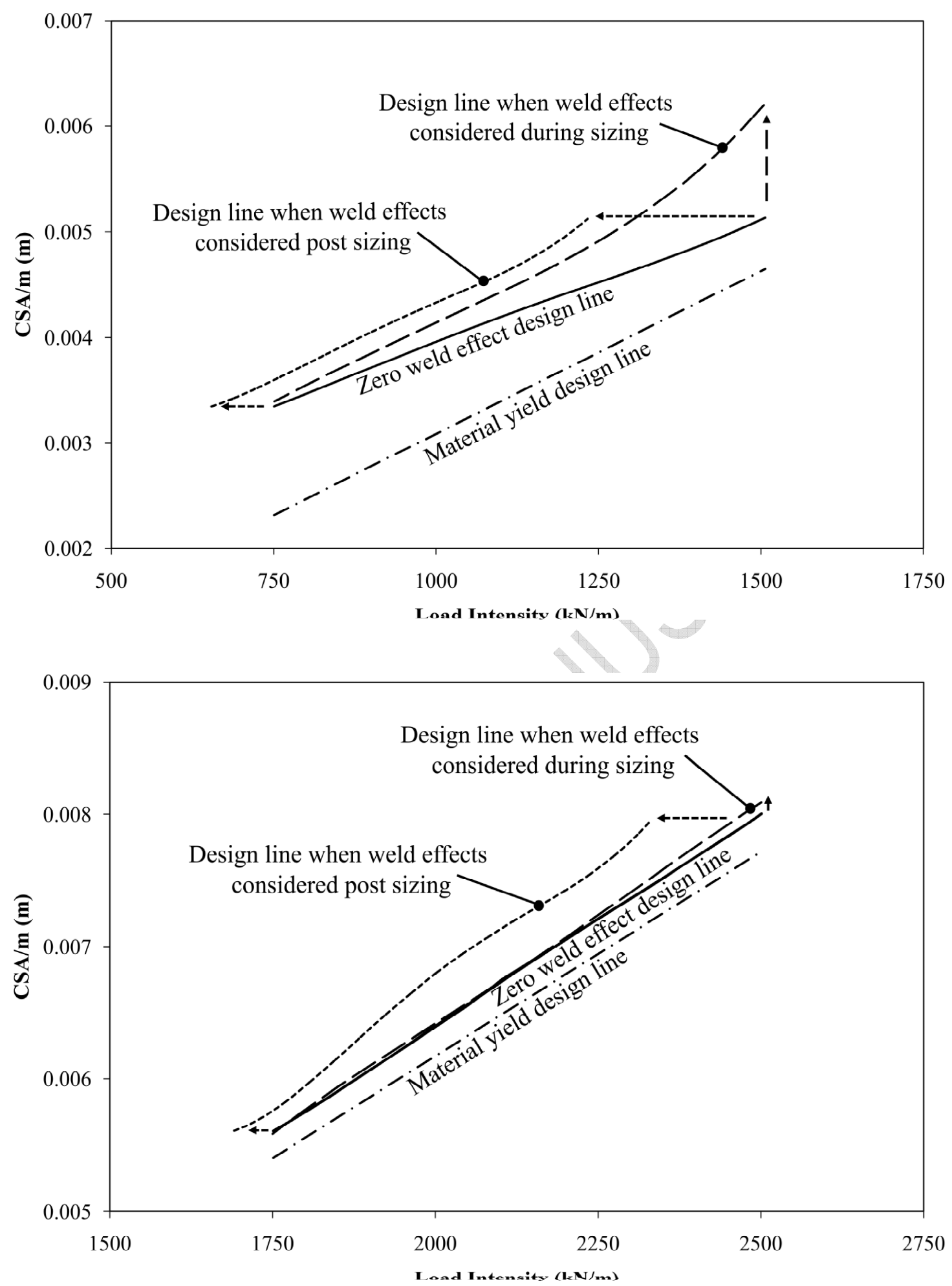

Figure 11 - Design study 1 results - Inclusion of weld effects 

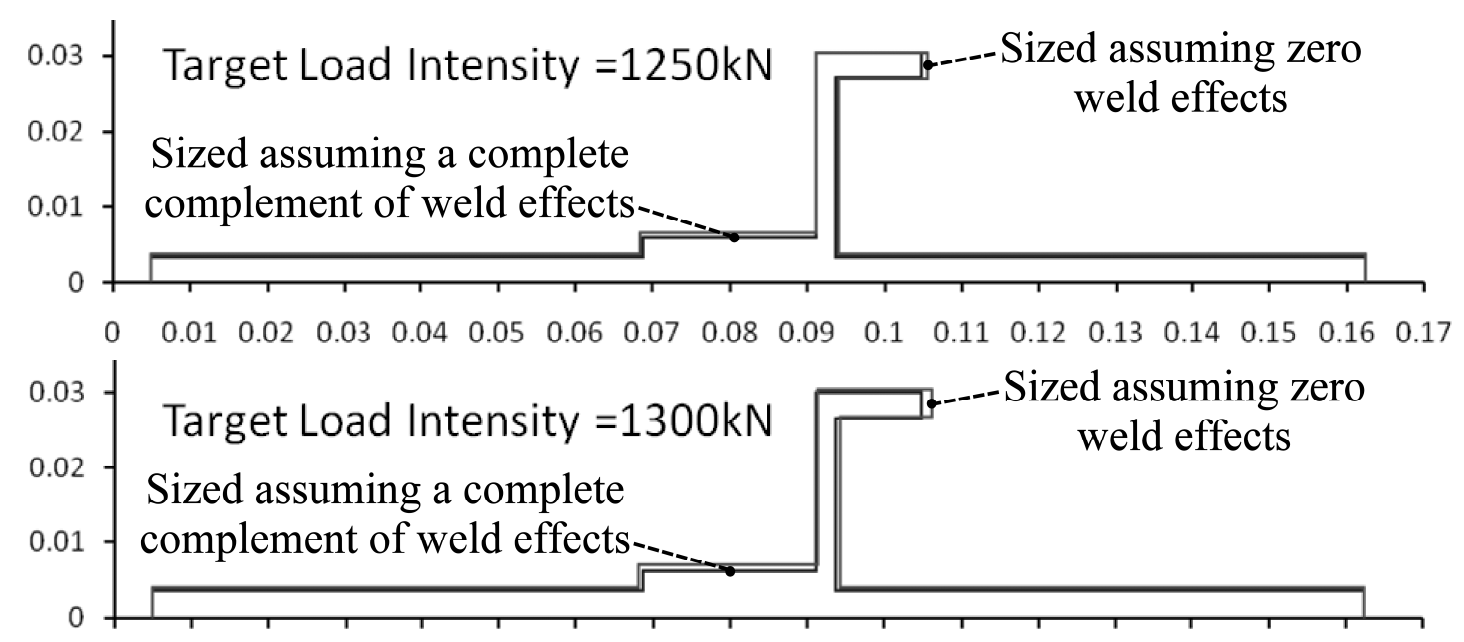

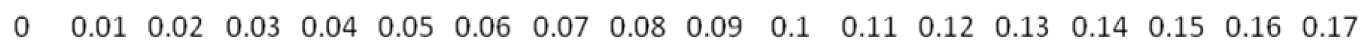

$0.03-$ Target Load Intensity $=1350 \mathrm{kN}$

0.02

complement of weld effects
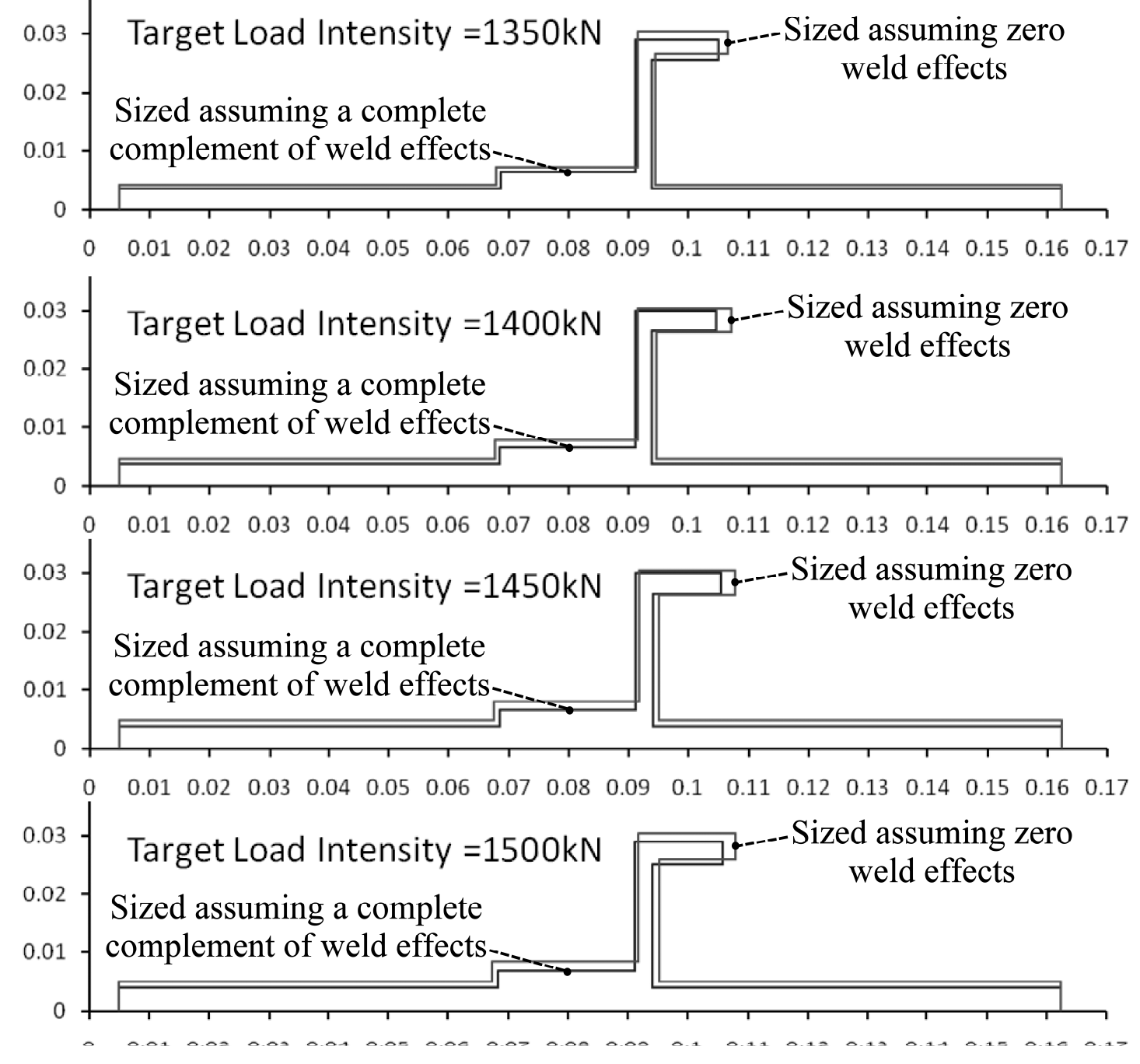

Figure 12 - Design study 1 - Fuselage design cross-sections (all dimensions given in $\mathrm{mm})$. 

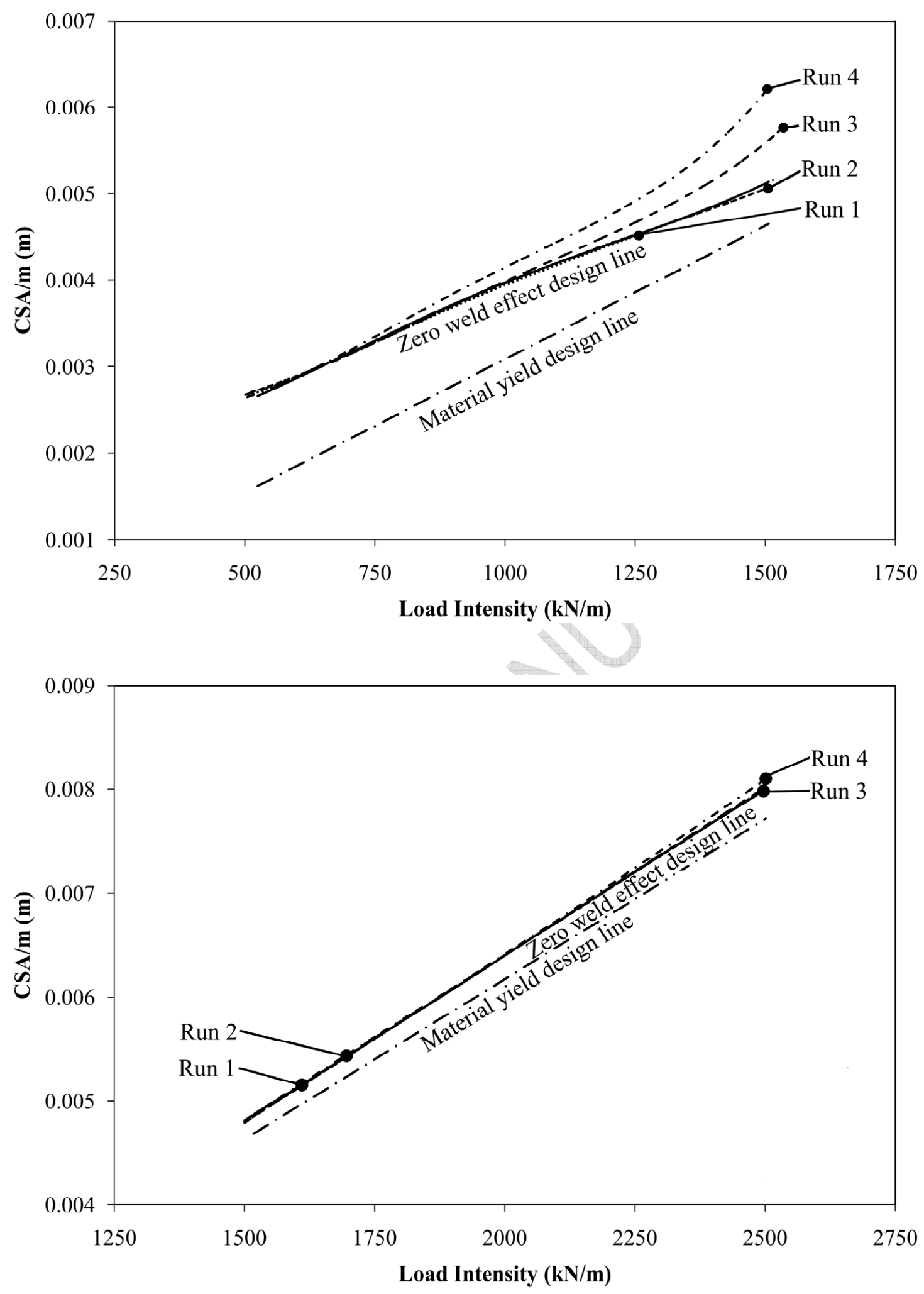

Figure 13 - Design study 2 results - Weld effect magnitudes 